\title{
Nova espécie de Miconia Ruiz \& Pav. (Melastomataceae) para Minas Gerais, Brasil
}

\author{
José Fernando Andrade Baumgratz ${ }^{1,3}$ e Berenice Chiavegatto ${ }^{2}$
}

Recebido em 7/07/2005. Aceito em 21/11/2005

\begin{abstract}
RESUMO - (Nova espécie de Miconia Ruiz \& Pav. (Melastomataceae) para Minas Gerais, Brasil). É descrita e ilustrada uma nova espécie de Miconia para o Parque Estadual do Ibitipoca, Minas Gerais - Miconia kriegeriana Baumgratz \& Chiavegatto - pertencente à seção Glossocentrum (Crueger) Hook. Caracteriza-se, principalmente, pela lâmina foliar bulada, brácteas e profilos crassos e involucrais, cálice 4-6-mero e 12-19 estames. Comenta-se também sobre diferenças morfológicas em relação às espécies próximas, incluindo da seção Miconia ser. Glomeratiflorae Naudin e ser. Seriatiflorae Naudin.
\end{abstract}

Palavras-chave : Miconia, Melastomataceae, campo rupestre, Minas Gerais

ABSTRACT - (New species of Miconia Ruiz \& Pav. (Melastomataceae) from Minas Gerais State, Brazil). A new species of Miconia from Parque Estadual do Ibitipoca, Minas Gerais is described and illustrated - Miconia kriegeriana Baumgratz \& Chiavegatto. This species belongs to the section Glossocentrum (Crueger) Hook. and it is characterized by the bullate leaves, bracts and profiles thick and clustered, calyx 4-6-merous and 12-19 stamens. Comments are presented about morphological differences towards related species, including the section Miconia ser. Glomeratiflorae Naudin and ser. Seriatiflorae Naudin.

Key words: Miconia, Melastomataceae, campo rupestre, Minas Gerais

\section{Introdução}

As Melastomataceae, incluindo Memecylaceae, constituem uma numerosa família pantropical e subtropical, com mais de 4.500 espécies (Clausing \& Renner 2001), floristicamente abundante e diversificada na América do Sul. No Brasil, encontram-se ca. 1.500 espécies, distribuídas em 66 gêneros e ocorrendo principalmente em áreas tropicais (Baumgratz \& Souza 2005).

Miconia Ruiz \& Pav. é o gênero com maior número de espécies na família, ocorrendo desde o sul do México até a Argentina. No Brasil, as espécies ocorrem em diferentes ecossistemas, desde o nível do mar, nas restingas, até as florestas alto-montanas, no domínio da Mata Atlântica, bem como em formações vegetacionais na região central do país, como os cerrados e os campos rupestres.
Uma nova espécie de Miconia foi encontrada durante o recente estudo sobre a diversidade taxonômica das Melastomataceae nos campos rupestres do Parque Estadual do Ibitipoca, localizado no município de Lima Duarte, Minas Gerais. A inconsistência da classificação do gênero Miconia proposta por Cogniaux $(1887-1988,1891)$ tem sido assinalada por vários autores (Baumgratz \& Souza 2004; Goldenberg 2004; Wurdack 1962), que comentam sobre a fragilidade dos limites das categorias infragenéricas e a incongruência de suas características diagnósticas com as respectivas descrições. Conseqüentemente, isso dificulta o enquadramento de espécies recém descobertas em uma das categorias, seja no nível de seção e/ou série, ao mesmo tempo em que faculta diferentes possibilidades de posicionamento e análises de relações interespecíficas, conforme se observa também para M. kriegeriana.

\footnotetext{
1 Instituto de Pesquisas Jardim Botânico do Rio de Janeiro, Programa Diversidade Taxonômica; Bolsista de Produtividade/CNPq

2 Escola Nacional de Botânica Tropical do Instituto de Pesquisa Jardim Botânico do Rio de Janeiro, Rua Pacheco Leão 915, CEP 22460-030, Rio de Janeiro, RJ, Brasil

3 Autor para correspondência: jbaumgra@jbrj.gov.br
} 


\section{Resultados e discussão}

\section{Miconia kriegeriana Baumgratz \& Chiavegatto, sp. nov.}

Fig. 1a-n

Tipo: Brasil, Minas Gerais, Lima Duarte, Parque Estadual do Ibitipoca, trilha para o Monjolinho, 2142'26”S, 4359'02,2”; 15/VI/2004, fl., fr., B. Chiavegatto 87, J.F.A. Baumgratz, M.O. Afonso \& L.M. Neto (Holótipo - RB; Isótipos - CESJ, SPF).

Species nova praesertim margine, subtus pilis stellatis et 5 nervis foliorum et inflorescentiarum cum M. cineracens optime congruens, sed differt bracteis et profiliis crassis involucratis, foliis supra bulatis, subtus indumento sparsis vestitis superficie expositis, floribus pedicellatis, calycis 4-6-meris, 12-19 staminis, stylis 12-13 mm longis.

Arvoretas 2,5-3 m alt.; indumento dos ramos, folhas, inflorescências, brácteas, profilos, hipanto, face adaxial das lacínias do cálice e frutos densa a esparsamente estrelado-tomentoso, tricomas pedicelados e sésseis, caducos. Ramos jovens achatados, adultos cilíndricos. Pecíolo 0,7-1,4 cm compr.; lâmina 4,6-16,5×2-7,3 cm, discolor, face adaxial verde-escura a castanha, bulada, face abaxial verdeclara a pardacenta, nitidamente reticulada, superfície epidérmica exposta, não totalmente recoberta pelo indumento, cartácea, elíptica, oblongo-elíptica ou estreito-ovada, base obtusa a arredondada, às vezes aguda, ápice agudo, acuminado ou atenuadoacuminado, margem ondulada a denticulada, espessa, revoluta; 5 nervuras acródromas basais ou as mais internas até $1 \mathrm{~mm}$ suprabasais, estas e nervuras secundárias transversais nitidamente proeminentes na face abaxial. Tirsóides de glomérulos 6-10 cm compr., terminais, oblongos; pedúnculo 1,3-2,4 cm compr.; brácteas foliáceas $3,5-4 \times 1,5-2 \mathrm{~cm}$, não involucrais, estreito-elípticas a oblongas, pecioladas; brácteas crassas, não foliáceas, ca. $12 \times 3 \mathrm{~mm}$, involucrais, estreito-triangulares, ápice acuminado, margem ondulada, persistentes ou tardiamante caducas; profilos ca. 3,5×2,5 mm, crassos, involucrais, obovados, ápice obtuso a arredondado, persistentes ou tardiamente caducos. Flores com pedicelo 0,2-0,3 mm compr.; hipanto 4-4,5×4,5-5 mm, campanulado; zona do disco glabra; cálice de tetrâmero a hexâmero, tardia e circuncisamente caduco, tubo inconspícuo, lacínias bilobadas, eretas, as externas ca. $0,5 \times 0,5 \mathrm{~mm}$, inconspicuamente denticuladas, obscurecidas pelo indumento, as internas ca. $1,7 \times 1,7 \mathrm{~mm}$, triangulares, ápice agudo, face adaxial glabra; corola pentâmera, pétalas 3-3,2×2-2,5 $\mathrm{mm}$, alvas, reflexas, obovadas, ápice arredondado a emarginado, assimétrico, unilateralmente unilobado, papilosas; 12-19 estames, alvos, subisomórficos, subiguais em tamanho, filetes 3-4 mm, filiformes, anteras 3-4 mm compr., oblongas com base atenuada, poro terminal-ventral, conectivo prolongado 1-1,5 $\mathrm{mm}$ abaixo das tecas, geralmente inapendiculado, às vezes com apêndice lateralmente bilobulado; ovário 2-2,5×2-2,5 mm, 1/2-ínfero, 3-locular, glabro; estilete 12-13 mm, dilatado no ápice; estigma capitado. Bacáceos 4-6×4-5 mm, atropurpúreos, polispérmicos; sementes $21-25$, ca. $2,5 \times 2 \mathrm{~mm}$, sublenticulariformes a obovadas, às vezes obovadotriangulares, superfície lisa.

Parátipos: BRASIL. Minas Gerais: Lima Duarte, Parque Estadual do Ibitipoca, trilha para o Monjolinho, 15/VI/2004, fl., B. Chiavegatto et al. 85 (CEPEC, FLOR, RB, SP); subida para o Monjolinho, 25/XI/2004, fl., B. Chiavegatto et al. 123 (CESJ, HUFU, RB).

Etimologia: o epíteto kriegeriana é em homenagem ao Pe. Leopoldo Krieger, fundador do Herbário CESJ, da Universidade Federal de Juiz de Fora, MG, e coletor pioneiro no Parque Estadual do Ibitipoca.

Espécie restrita ao Parque Estadual do Ibitipoca, onde ocorre, geralmente, em áreas de transição entre o campo rupestre e formações florestais. Floresce e frutifica de novembro a junho.

As principais características diagnósticas desta espécie são a face adaxial da lâmina foliar bulada, inflorescências em glomérulos, brácteas crassas, não foliáceas, e profilos involucrais, persistentes ou tardiamente caducos, nítida variação do número de lacínias do cálice, de 4 a 6 , e dos estames, 12 a 19 , além do conectivo inapendiculado na maioria dos estames e, às vezes, com dois lóbulos laterais.

Por apresentar anteras oblongas, com base atenuada, uniporadas e conectivo geralmente inapendiculado, esta espécie enquadra-se mais adequadamente na seção Glossocentrum. Das espécies desta seção, aproxima-se de $M$. cinnerascens Miquel pelo conjunto de caracteres relacionados: lâmina foliar com margem crenulada a denticulada, face abaxial com indumento constituído de tricomas estrelados e cinco nervuras acródromas, inflorescências de glomérulos, cinco pétalas. Entretanto, esta espécie difere, principalmente, pela lâmina foliar com a face adaxial não bulada e a face abaxial com indumento revestindo totalmente a superfície epidérmica, brácteas e profilos não involucrais, 


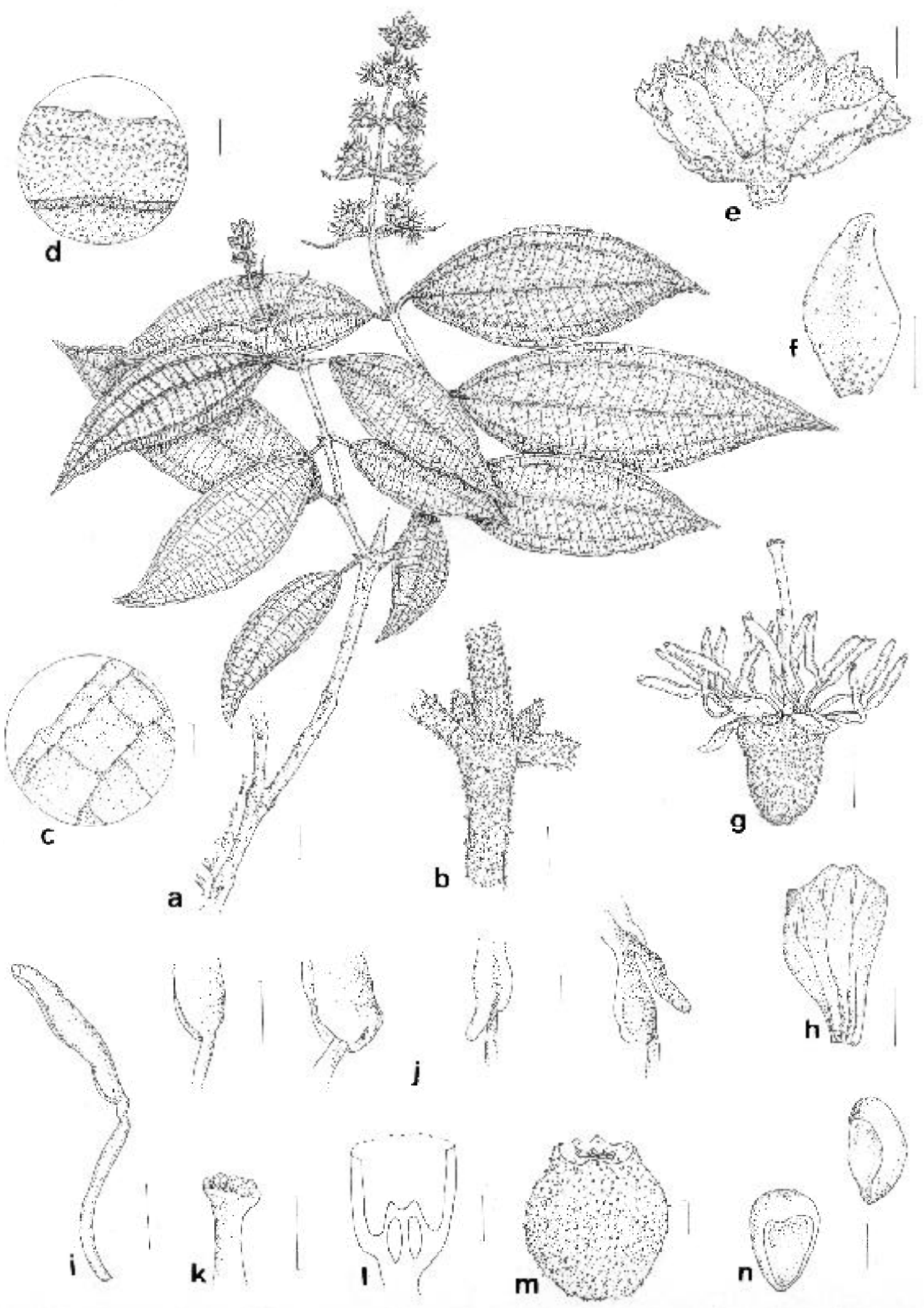

Figura 1. Miconia kriegeriana Ruiz \& Pav. a. Ramo florífero. b. Detalhe do ramo. c-d. Detalhe das faces adaxial e abaxial da lâmina foliar, respectivamente. e. Detalhe de um glomérulo evidenciando brácteas involucrais. f. Profilo. g. Flor. h. Pétala, com ápice infletido. i. Estame. j. Base da antera evidenciando ausência ou presença de apêndice do conectivo, vista polar dorsal. k. Ápice do estilete e estigma. 1. Secção longitudinal do ovário. m. Bacáceo. $\mathrm{n}$. Sementes (B. Chiavegatto et al. 123 ). Escalas: a = $1 \mathrm{~cm}, \mathrm{~b}-\mathrm{c}, \mathrm{e}-\mathrm{g}=2 \mathrm{~mm} ; \mathrm{d}, \mathrm{h}-\mathrm{i}, \mathrm{k}-\mathrm{n}=1 \mathrm{~mm}$; $\mathrm{j}=0,5 \mathrm{~mm}$. 
flores sésseis, cálice 4-6-mero, 10-12 estames e menor comprimento (ca. $4 \mathrm{~mm}$ ) do estilete.

Entretanto, observa-se uma inconsistência das circunscrições das seções estabelecidas por Cogniaux (1887-1888), pois características diagnósticas de algumas seções mostram-se incongruentes com descrições de espécies nelas enquadradas. Desse modo, pelas inflorescências com ramos não espiciformes, flores dispostas em glomérulos e anteras oblongas, uniporadas, com conectivo às vezes bilobulado na base, poderia ser integrada à seção Miconia ser. Glomeratiflorae, próxima a Miconia warmingiana Cogn., principalmente, pelos pecíolos curtos (0,7-1,4 cm), lâmina foliar oblonga, ápice agudo a atenuado-acuminado, com a face abaxial estreladotomentosa e cálice caduco. Entretanto, esta espécie difere pela face adaxial das folhas não bulada, brácteas e profilos não involucrais, flores sésseis, pétalas de dimensões menores $(1,5-2 \times$ ca. $1 \mathrm{~mm})$, cálice pentâmero, com lobos internos arredondados, estames em número de 10 , menor comprimento dos filetes (ca. $2 \mathrm{~mm})$, anteras $(1,-1,7 \mathrm{~mm})$ e estilete $(3-4 \mathrm{~mm}) \mathrm{e}$ frutos oligospérmicos. Poderia ainda se enquadrar na ser. Seriatiflorae, se aproximando de Miconia pulchra Cogn. pelo indumento estrelado-tomentoso e pelo estilete com ápice dilatado. Entretanto, esta difere pelas faces adaxial e abaxial da lâmina foliar planas, base aguda, nervuras acródromas basais, inflorescências escorpiódes, 20 estames e conectivo inapendiculado.

\section{Agradecimentos}

Aos curadores dos herbários citados, pelos empréstimos concedidos e envio de fotografias; à Dra.
Maria Leonor D'El Rei Souza, da Universidade Federal de Santa Catarina, pelas sugestões; ao Dr. Jefferson Prado, do Instituto de Botânica, São Paulo, pela revisão da diagnose latina; à Maria Alice Rezende, pela ilustração em nanquim; ao Instituto Estadual de Florestas de Minas Gerais e à Administração do Parque Estadual do Ibitipoca, pela licença de coleta e apoio técnico e logístico; ao CNPq e CAPES, pelas bolsas concedidas ao primeiro e segundo autores, respectivamente.

\section{Referências bibliográficas}

Baumgratz, J.F.A. \& Souza, M.L.D.R. 2004. Two new species of Miconia (Melastomataceae) from Bahia, Brazil. Bradea 10: 1 25-33.

Baumgratz, J.F.A. \& Souza, M.L.D.R. 2005. Novas espécies de Leandra Raddi (Melastomataceae) para o Estado de São Paulo, Brasil. Acta Botanica Brasilica 19(3): 561-566.

Clausing, G. \& Renner, S.S. 2001. Molecular Phyllogenetics of Melastomataceae and Memecylaceae: implications for character evolution. American Journal of Botany 88: 486-498.

Cogniaux, C.A. 1887-1888. Miconia Ruiz \& Pav. (Melastomataceae). Pp. 213-424. In: C.F.P. Martius \& A.G. Eichler (eds.). Flora Brasiliensis 14(4). Frid Fleischer., München.

Cogniaux, C.A. 1891. Melastomataceae. Pp. 1-1256. In: A. \& C. de Candolle (eds.). Monographiae Phanerogamarum 7. Paris, G. Masson.

Goldenberg, R. 2004. O gêneroMiconia (Melastomataceae) no Estado do Paraná, Brasil. Acta Botanica Brasilica 18(4): 927-947.

Wurdack, J.J. 1962. Melastomataceae of Santa Catarina. Sellowia 14: 109-217. 